\title{
SUFFICIENT CONDITIONS FOR MEROMORPHIC STARLIKENESS AND CLOSE-TO-CONVEXITY OF ORDER $\alpha$
}

\author{
NAK EUN CHO and SHIGEYOSHI OWA
}

(Received 7 February 2000)

\begin{abstract}
The object of the present paper is to derive a property of certain meromorphic functions in the punctured unit disk. Our main theorem contains certain sufficient conditions for starlikeness and close-to-convexity of order $\alpha$ of meromorphic functions.
\end{abstract}

2000 Mathematics Subject Classification. 30C45.

1. Introduction. Let $\sum$ denote the class of functions of the form

$$
f(z)=\frac{1}{z}+\sum_{n=1}^{\infty} a_{n} z^{n}
$$

which are analytic in the punctured unit disk $\mathscr{D}=\{z: 0<|z|<1\}$. A function $f \in \sum$ is said to be meromorphic starlike of order $\alpha$ if it satisfies

$$
-\operatorname{Re}\left\{\frac{z f^{\prime}(z)}{f(z)}\right\}>\alpha \quad(z \in \mathcal{U}=\mathscr{D}-\{0\})
$$

for some $\alpha(0 \leq \alpha<1)$. We denote by $\sum^{*}(\alpha)$ the class of all meromorphic starlike functions of order $\alpha$.

Let $\mathrm{MC}(\alpha)$ be the subclass of $\sum$ consisting of functions $f$ which satisfy

$$
-\operatorname{Re}\left\{z^{2} f^{\prime}(z)\right\}>\alpha \quad(z \in U)
$$

for some $\alpha(0 \leq \alpha<1)$. A function $f$ in $\mathrm{MC}(\alpha)$ is meromorphic close-to-convex of order $\alpha$ in $\mathscr{D}$ (see [1]).

2. Main result. In proving our main theorem, we need the following lemma due to Owa, Nunokawa, Saitoh, and Fukui [2].

LEMMA 2.1. Let $p$ be analytic in $u$ with $p(0)=1$. Suppose that there exists a point $z_{0} \in U$ such that $\operatorname{Re} p(z)>0\left(|z|<\left|z_{0}\right|\right), \operatorname{Re} p\left(z_{0}\right)=0$, and $p(z) \neq 0$. Then we have $p(z)=i a(a \neq 0)$ and

$$
\frac{z_{0} p^{\prime}\left(z_{0}\right)}{p\left(z_{0}\right)}=i \frac{k}{2}\left(a+\frac{1}{a}\right)
$$

where $k$ is a real number with $k \geq 1$.

With the aid of Lemma 2.1, we derive the following theorem. 
THEOREM 2.2. If $f \in \sum$ satisfies $f(z) f^{\prime}(z) \neq 0$ in $\mathscr{D}$ and

$$
\operatorname{Re}\left\{\alpha \frac{z f^{\prime}(z)}{f(z)}-\frac{z f^{\prime \prime}(z)}{f^{\prime}(z)}\right\}<2(2-\alpha)-\beta \quad(z \in \mathcal{U})
$$

then

$$
-\operatorname{Re}\left\{\frac{z^{2-\alpha} f^{\prime}(z)}{f^{\alpha}(z)}\right\}>\frac{1}{1+2(2-\alpha)-2 \beta} \quad(z \in u),
$$

where $\alpha \leq 2$ and $(2(2-\alpha)-1) / 2 \leq \beta<2-\alpha$.

Proof. We define the function $p$ in $u$ by

$$
-\frac{z^{2-\alpha} f^{\prime}(z)}{f^{\alpha}(z)}=\gamma+(1-\gamma) p(z)
$$

with $\gamma=1 /(1+2(2-\alpha)-2 \beta)$. Then $p$ is analytic in $U$ with $p(0)=1$ and

$$
\alpha \frac{z f^{\prime}(z)}{f(z)}-\frac{z f^{\prime \prime}(z)}{f^{\prime}(z)}=2-\alpha-\frac{(1-\gamma) z p^{\prime}(z)}{\gamma+(1-\gamma) p(z)} .
$$

Suppose that there exists a point $z_{0} \in \mathcal{U}$ such that

$$
\operatorname{Re} p(z)>0 \quad\left(|z|<\left|z_{0}\right|\right), \quad \operatorname{Re} p\left(z_{0}\right)=0, \quad p(z) \neq 0 .
$$

Then, applying Lemma 2.1, we have $p(z)=i a(a \neq 0)$ and

$$
\frac{z_{0} p^{\prime}\left(z_{0}\right)}{p\left(z_{0}\right)}=i \frac{k}{2}\left(a+\frac{1}{a}\right) \quad(k \geq 1) .
$$

It follows from this that

$$
\alpha \frac{z_{0} f^{\prime}\left(z_{0}\right)}{f\left(z_{0}\right)}-\frac{z_{0} f^{\prime \prime}\left(z_{0}\right)}{f^{\prime}\left(z_{0}\right)}=2-\alpha-\frac{(1-\gamma) z_{0} p^{\prime}\left(z_{0}\right)}{\gamma+(1-\gamma) p\left(z_{0}\right)}=2-\alpha+\frac{k(1-\gamma)\left(1+a^{2}\right)}{2(\gamma+i(1-\gamma) a)} .
$$

Therefore, we have

$$
\begin{aligned}
\operatorname{Re}\left\{\alpha \frac{z_{0} f^{\prime}\left(z_{0}\right)}{f\left(z_{0}\right)}-\frac{z_{0} f^{\prime \prime}\left(z_{0}\right)}{f^{\prime}\left(z_{0}\right)}\right\} & =2-\alpha+\frac{k(1-\gamma)\left(1+a^{2}\right)}{2\left(\gamma^{2}+(1-\gamma)^{2} a^{2}\right)} \\
& \geq 2-\alpha+\frac{k(1-\gamma)}{2 \gamma} \geq 2(2-\alpha)-\beta .
\end{aligned}
$$

This contradicts our assumption. Thus, we conclude that $\operatorname{Re} p(z)>0$ for all $z \in \mathcal{U}$, that is,

$$
-\operatorname{Re}\left\{\frac{z^{2-\alpha} f^{\prime}(z)}{f^{\alpha}(z)}\right\}>\gamma=\frac{1}{1+2(2-\alpha)-2 \beta} \quad(z \in \mathcal{u}) .
$$

Putting $\beta=(2(2-\alpha)-1) / 2$ in Theorem 2.2, we have

COROLlary 2.3. If $f \in \sum$ satisfies $f(z) f^{\prime}(z) \neq 0$ in $\mathscr{D}$ and

$$
\operatorname{Re}\left\{\alpha \frac{z f^{\prime}(z)}{f(z)}-\frac{z f^{\prime \prime}(z)}{f^{\prime}(z)}\right\}<\frac{3}{2}-\alpha \quad(z \in \mathcal{u})
$$

then

$$
-\operatorname{Re}\left\{\frac{z^{2-\alpha} f^{\prime}(z)}{f^{\alpha}(z)}\right\}>\frac{1}{2} \quad(z \in U)
$$

where $\alpha \leq 2$. 
Taking $\alpha=1$ in Theorem 2.2, we have the following corollary.

COROLLARY 2.4. If $f \in \sum$ satisfies $f(z) f^{\prime}(z) \neq 0$ in $\mathscr{D}$ and

$$
\operatorname{Re}\left\{\frac{z f^{\prime}(z)}{f(z)}-\frac{z f^{\prime \prime}(z)}{f^{\prime}(z)}\right\}<2-\beta \quad(z \in u),
$$

then

$$
-\operatorname{Re}\left\{\frac{z f^{\prime}(z)}{f(z)}\right\}>\frac{1}{3-2 \beta} \quad(z \in \mathcal{U}),
$$

that is, $f \in \sum^{*}(1 /(3-2 \beta))$, where $1 / 2 \leq \beta<1$.

Further, letting $\alpha=0$ in Theorem 2.2, we have the following corollary.

COROLlary 2.5. If $f \in \sum$ satisfies $f(z) f^{\prime}(z) \neq 0$ in $\mathscr{D}$ and

$$
-\operatorname{Re}\left\{\frac{z f^{\prime \prime}(z)}{f^{\prime}(z)}\right\}<4-\beta \quad(z \in U),
$$

then

$$
-\operatorname{Re}\left\{z^{2} f^{\prime}(z)\right\}>5-2 \beta \quad(z \in \mathcal{U}),
$$

that is, $f \in \mathrm{MC}(1 /(5-2 \beta))$, where $3 / 2 \leq \beta<2$.

ACKNOWLEDGEMENT. This work was supported by the Korea Research Foundation Grant (KRF-99-015-DP0019).

\section{REFERENCES}

[1] M. D. Ganigi and B. A. Uralegaddi, Subclasses of meromorphic close-to-convex functions, Bull. Math. Soc. Sci. Math. R. S. Roumanie (N.S.) 33(81) (1989), no. 2, 105-109. MR 91b:30036. Zbl 685.30004.

[2] S. Owa, M. Nunokawa, H. Saitoh, and S. Fukui, Starlikeness and close-to-convexity of certain analytic functions, Far East J. Math. Sci. 2 (1994), no. 2, 143-148. MR 97d:30014. Zbl 933.30008 .

Nak Eun Cho: Department of Applied Mathematics, Pukyong National University, PUSAN 605-737, KOREA

E-mail address: necho@dolphin.pknu.ac.kr

Shigeyoshi OWa: Department of Mathematics, Kinki University, Higashi-OSAKa, OSAKA 577-8502, JAPAN

E-mail address: owa@math.kindai .ac.jp 


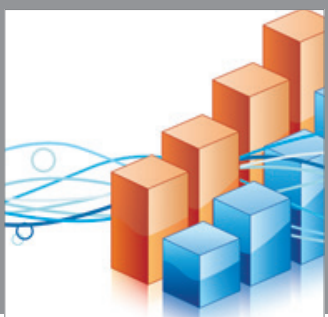

Advances in

Operations Research

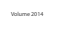

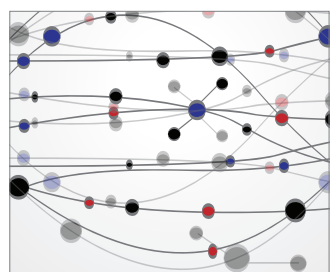

\section{The Scientific} World Journal
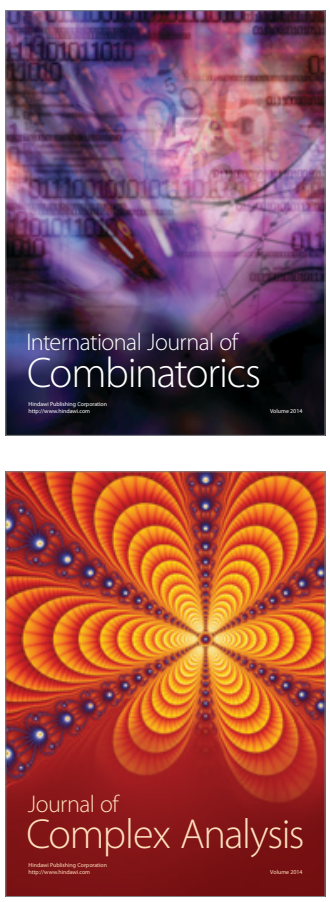

International Journal of

Mathematics and

Mathematical

Sciences
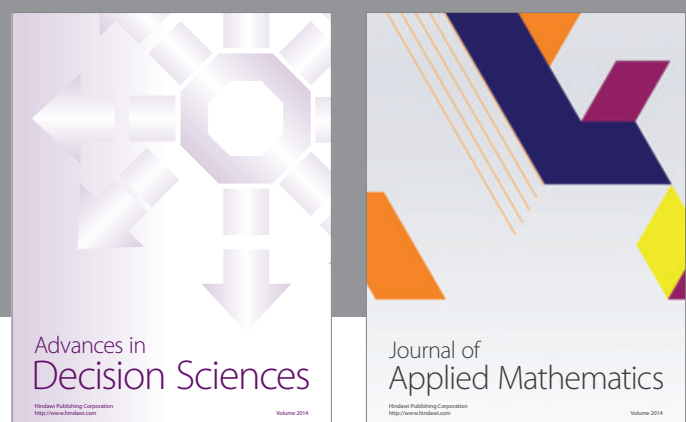

Journal of

Applied Mathematics
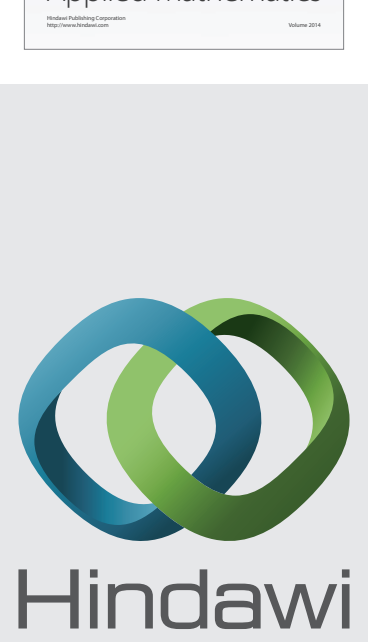

Submit your manuscripts at http://www.hindawi.com
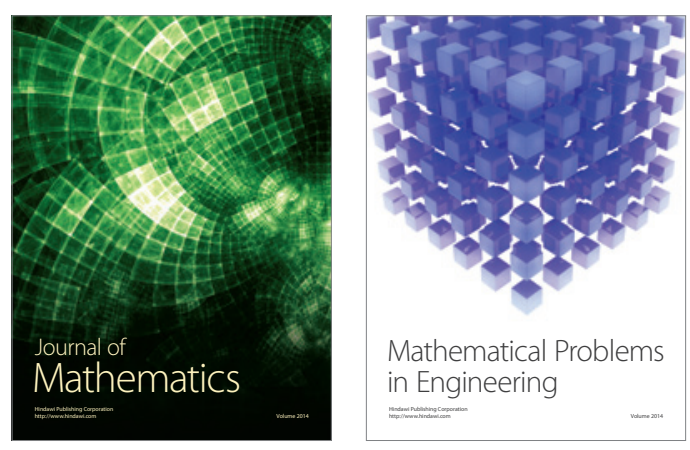

Mathematical Problems in Engineering
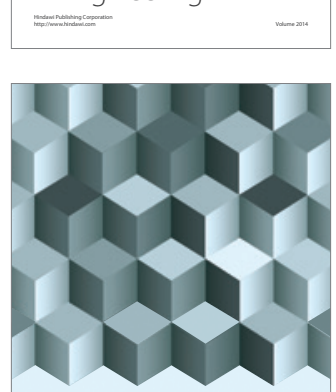

Journal of

Function Spaces
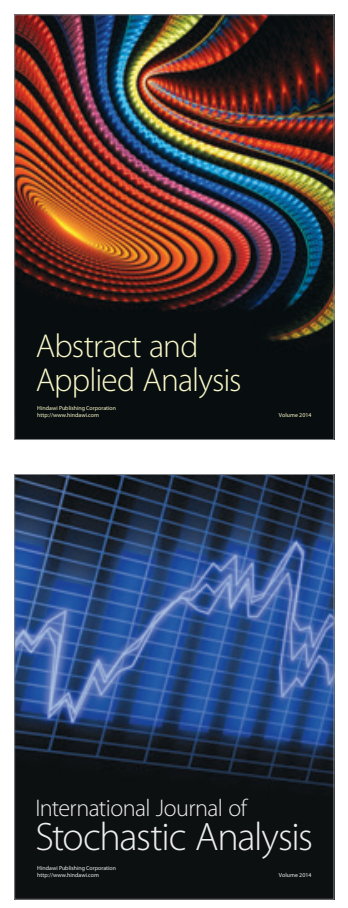

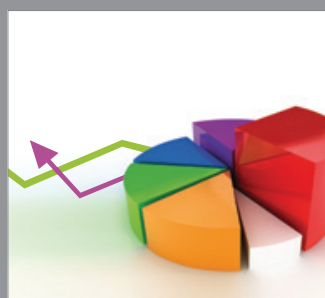

ournal of

Probability and Statistics

Promensencen
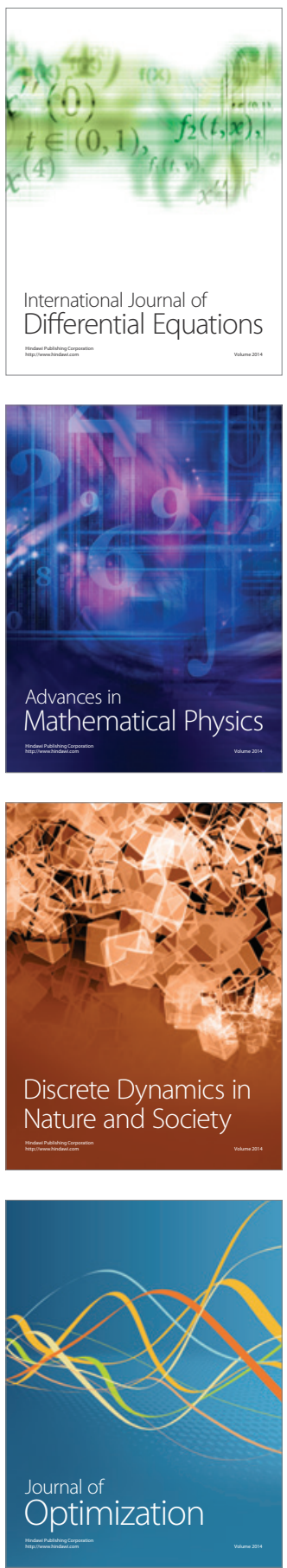